\title{
Aortic Stiffness in Patients with Deep and Lobar Intracerebral Hemorrhage: Role of Antihypertensive Drugs and Statins
}

\author{
Ercan Varol, Mehmet Ozaydin \\ Department of Cardiology, Suleyman Demirel University, Faculty of Medicine, Isparta, Turkey
}

\section{Dear Sir:}

Acampa et al. ${ }^{1}$ investigated arterial stiffness in patients with deep intracerebral hemorrhage ( $\mathrm{ICH})$ in comparison with that in patients with lobar ICH. The arterial stiffness index was significantly higher in the patients with deep ICH than in the patients with lobar ICH. This is a well-written study. However, we want to mention the associated drugs used by patients that can affect arterial stiffness.

Arterial stiffness is a complex process associated with confounding factors. Cecelja et al. ${ }^{2}$ published a systematic review that showed that the contribution of cardiovascular risk factors, other than age and blood pressure, to aortic stiffness measured by carotid-femoral pulse wave velocity is small or insignificant and that age and blood pressure were consistently independently associated with aortic stiffness. It has also been shown that some antihypertensive drugs like angiotensin-converting enzyme inhibitors, calcium channel blockers, and spironolactone reduce arterial stiffness. ${ }^{3-5} \mathrm{~A}$ recent study ${ }^{5}$ showed that in addition to angiotensin-converting enzyme inhibitors, beta blockers and aliskiren, a direct renin inhibitor, reduce arterial stiffness. The Acampa et al. study ${ }^{1}$ included 39 hypertensive patients in deep $\mathrm{ICH}$ group 1 and 15 in lobar ICH group 2. However, there are no details regarding the antihypertensive drugs used. Similarly, statins reduce arterial stiffness, ${ }^{3}$ but there are no details regarding their use. Thus, antihypertensive drugs and statins should be considered in aortic stiffness evaluations. It would be helpful if the authors provided this information.

\section{References}

1. Acampa M, Guideri F, Di Donato I, Tassi R, Marotta G, Lo Giudice $G$, et al. Arterial stiffness in patients with deep and lobar intracerebral hemorrhage. J Stroke 2014;16:184-188.

2. Cecelja M, Chowienczyk P. Dissociation of aortic pulse wave velocity with risk factors for cardiovascular disease other than hypertension: a systematic review. Hypertension 2009;54:13281336.

3. Cavalcante JL, Lima JA, Redheuil A, Al-Mallah MH. Aortic stiffness: current understanding and future directions. J Am Coll Cardiol 2011;57:1511-1522.

4. Dudenbostel T, Glasser SP. Effects of antihypertensive drugs on arterial stiffness. Cardiol Rev 2012;20:259-263.

5. Koumaras C, Tziomalos K, Stavrinou E, Katsiki N, Athyros VG, Mikhailidis DP, et al. Effects of renin-angiotensin-aldosterone system inhibitors and beta-blockers on markers of arterial stiffness. J Am Soc Hypertens 2014;8:74-82.

Correspondence: Ercan Varol

Suleyman Demirel Univesitesi, Tip Fakultesi, Isparta, Turkey

Tel: +90-5323468258, Fax: +90-24623245

E-mail: drercanvarol@yahoo.com

Received: Otober 22, 2014

Revised: November 12, 2014

Accepted: November 13, 2014

The authors have no declaration of interest. 